UCRL-ID-114158

\title{
Report on the Radiochemical and Environmental Isotope Character for Monitoring Well UE-1-q: Groundwater Characterization Program
}

\author{
Nuclear Chemistry Division
}

M. L. Davisson

G. B. Hudson

J. Kenneally

G. J. Nimz

J. H. Rego

June 1993

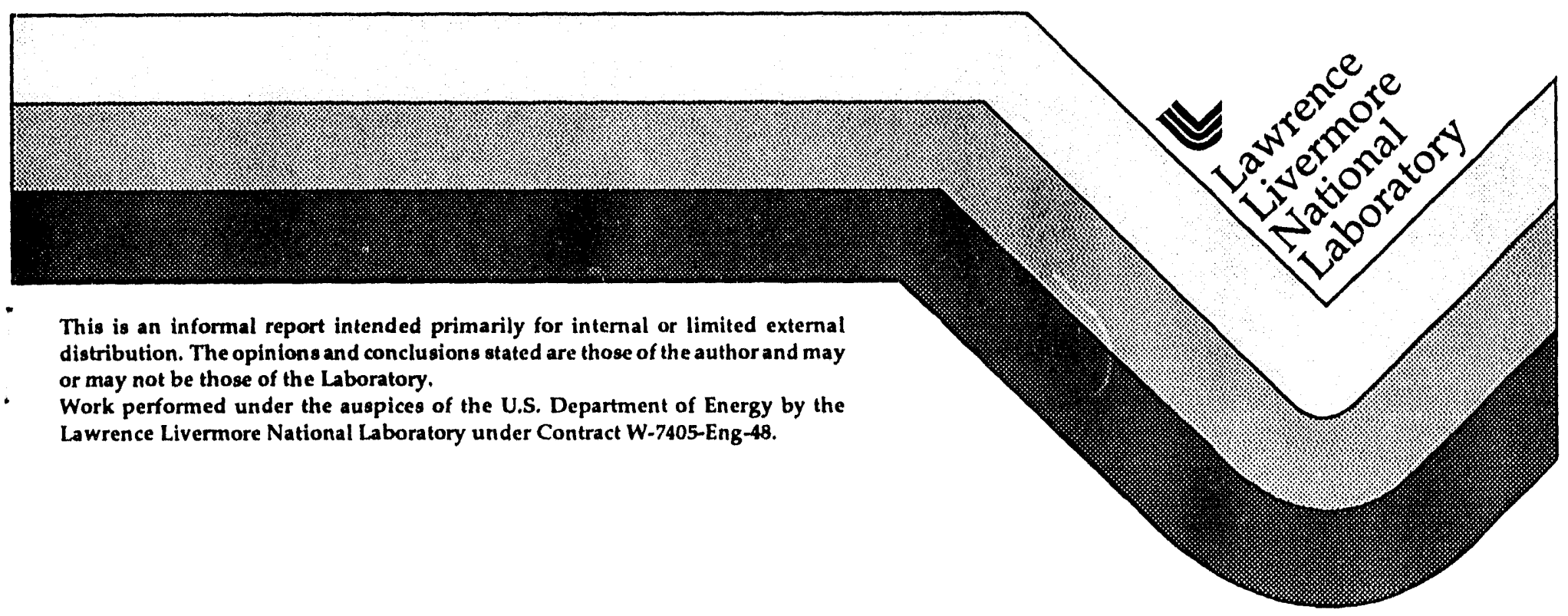




\section{DISCLAIMER}

This document was prepared as an account of work sponsored by an agency of the United States Government. Neither the United States Government nor the University of California nor any of their employees, makes any warranty, express or implied, or assumes any legal liability or responsibility for the accuracy, completeness, or usefulness of any information, apparatus, product, or process disclosed, or represents that its use would not infringe privately owned rights. Reference herein to any specific commercial products, process, or service by trade name, trademark, manufacturer, or otherwise, does not necessarily constitute or imply its endorsemenh, recommendation, or favoring by the United States Government or the University of Califormia. The views and opinions of authors expressed her ein do not necessarily state or reflect those of the United States Government or the University of California, and shall not be used for advertising or product endorsement purposes.

This report has been reproduced directly from the best a vailable copy.

A vailable to DOE and DOE contractors from the Office of Scientific and Technical Information

P.O. Box 62, Oak Ridge, TN 37831

Prices available from (615) 576.8401, FTS 626.8401

A vailable to the public from the

National Technical Information Service

US. Department of Commerce

5285 Port Royal Rd.

Springfield, VA 22161 
REPORT ON THE RADIOCHEMICAL AND ENVIRONMENTAL ISOTOPE

CHARACTER FOR MONITORING WELL UE-1-q: GROUNDWATER

CHARACTERIZATION PROGRAM

\author{
Nuclear Chemistry Division \\ Lawrence Livermore Lab
}

by

M.L. Davisson

G.B. Hudson

J. Kenneally

G.J. Nimz

J.H. Rego 


\section{INTRODUCTION}

Well UE-1-q is located in the northeastern portion of area 1 of the Nevada Test Site (NTS; Fig 1) in southwestern Nevada, 1244.1 meters above sea level. The well was originally an exploratory hole drilled to a depth of 74.3 meters below the surface (mbs) by LANL in November of 1980. In May 1992, the Groundwater Characterization Program (GCP) extended the total depth to approximately $792.5 \mathrm{mbs}$. UE-1-q is cased to a total depth of $749.5 \mathrm{mbs}$, with the remaining uncased depth exposed exclusively to Paleozoicaged carbonate rock, the principle zone of groundwater sampling. Geologic logging indicates approximately 390 meters of tuffaceous and calcareous alluvium overlies 320 meters of Tertiary-aged volcanic ash-flow and bedded tuffs. Paleozoic carbonate lithology extends from $716 \mathrm{mbs}$ to the total well depth and is separated from the overlying Tertiary volcanic deposits by 6 meters of paleocolluvium.

This report outlines the results and interpretations of radiochemical and environmental isotopic analyses of groundwater sampled from UE-1-q on July 10, 1992 during the well pump test following well development. In addition, results of the field tritium monitoring performed during the well drilling are reported in Appendix 1. Sampling, analytical techniques, and analytical uncertainties for the groundwater analyses are presented in Appendix 2.

\section{RESULTS}

Radionuclides- The radionuclides ${ }^{60} \mathrm{Co},{ }^{125} \mathrm{Sb},{ }^{137} \mathrm{Cs},{ }^{90} \mathrm{Sr},{ }^{99} \mathrm{Tc},{ }^{85} \mathrm{Kr}$ and ${ }^{3} \mathrm{H}$ comprise the suite of radiochemical analyses for GCP. These radionuclides are commonly found in cavities of subsurface nuclear test sites, and except for the ${ }^{3} \mathrm{H}$, are unnatural to the groundwater environment within detectable limits. Their moderate to long half-lives make them ideal radioactive contaminant tracers of nuclear cavity products. All concentrations for these constituents are helow detectahle limits in groundwater from UE- 
1-q as shown in Table 1. In addition, the levels are far below the maximum permissible concentrations for potable groundwater as listed below:

$\begin{array}{ll}\text { Tritium }\left({ }^{3} \mathrm{H}\right) & 20,000 \mathrm{pCi} / \mathrm{L} \\ \text { Strontium- } 90\left({ }^{90} \mathrm{Sr}\right) & 8 \mathrm{pCi} / \mathrm{L} \\ \text { Cesium-1.37 }\left({ }^{137} \mathrm{Cs}\right) & 7400 \mathrm{pCi} / \mathrm{L} \\ \text { Uranium (total) } & 20 \mathrm{pCi} / \mathrm{L}\end{array}$

Environmental Isotopes - Aside from the anthropogenic radionuclide tracers, the environmental isotope systems of ${ }^{36} \mathrm{Cl} / \mathrm{Cl},{ }^{14} \mathrm{C},{ }^{87} \mathrm{Sr} /{ }^{86} \mathrm{Sr},{ }^{234} \mathrm{U} / 238 \mathrm{U},{ }^{3} \mathrm{He} /{ }^{4} \mathrm{He}$, and noble gas abundances were analyzed in order to characterize the age and natural source of the groundwater. All results are reported in Table 1 and their significance is discussed in the Discussion section below.

The ${ }^{14} \mathrm{C}$ content in the water sample is reported as a fraction of modern carbon (pmc) relative to a standard (NBS Oxalic Acid) after Stuiver and Polach, (1977), and is 0.0765 as listed in Table 1. An uncorrected groundwater age of 20,650 years is reported and a younger ${ }^{13} \mathrm{C}$ corrected age is presented and both are discussed below. The ${ }^{36} \mathrm{Cl}$ is reported as a ratio to total chloride in the groundwater sample. The ${ }^{36} \mathrm{Cl} / \mathrm{Cl}$ ratio is $7.90 \mathrm{x}$ $10^{-13}$ which yields a ${ }^{36} \mathrm{Cl}$ atom abundance of $7.1 \times 10^{7 / l i t e r}$. The ${ }^{234} \mathrm{U} / 238 \mathrm{U}$ ratio for groundwater from UE-1-q is 0.000268 which yields an activity ratio of 4.9 , and both are reported in Table 1. The ${ }^{87} \mathrm{Sr} / 86 \mathrm{Sr}$ ratio of the groundwater from UE-1-q is 0.7113 . The ${ }^{3} \mathrm{He} /{ }^{4} \mathrm{He}$ ratio is $9.2 \times 10^{-7}$ and the radiogenic ${ }^{4} \mathrm{He}$ concentration is $1.76 \times 10^{12}$ (Table 1 ). The non-radiogenic noble gas abundances are typical values for meteorically derived groundwater from ambient temperatures. 


\section{DISCUSSION}

Radiochemistry

Most radionuclide characterization of groundwater at the NTS has been in the analysis of water from or near detonation cavities (Borg et al., 1976; Crow, 1976; Bryant, 1992). Radionuclides analyzed for the GCP are common fission products ( $85 \mathrm{Kr}$ and $\left.{ }^{99} \mathrm{Tc}\right)$, neutron activation products $\left({ }^{60} \mathrm{Co}\right)$, or result from decay of short-lived fission products $\left({ }^{90} \mathrm{Sr},{ }^{137} \mathrm{Cs},{ }^{125} \mathrm{Sb},{ }^{85} \mathrm{Kr}\right.$, and $\left.{ }^{99} \mathrm{Tc}\right)$ produced from a nuclear test (Borg et al., 1976; Bryant, 1992). The activity level of any particular one of these radionuclides in the groundwater depends on the magnitude of the test and its geologic response (Borg et al., 1976).

Krypton-85 is in a dissolved gas phase and has a higher rate of mobility within the groundwater than ${ }^{90} \mathrm{Sr}$ and ${ }^{137} \mathrm{Cs}$ which tend to be immobile and absorb to rock material, although their fission product precursors were volatile nuclides with a high potential for migration. Technetium-99 is mobile in oxidized waters, whereas ${ }^{60} \mathrm{Co}$ and ${ }^{125} \mathrm{Sb}$ tend to have a low mobility and an alfinity to rock absorption. Tritium formed during a subsurface detonation is bound into molecular water and is incorporated into the groundwater mass. Activity levels in nuclear detonation cavities can be very high (avg. $\left.{ }^{3} \mathrm{H} \sim 1 \times 10^{9} \mathrm{pCi} / \mathrm{L}\right)$, whereas activities detected outside of cavities tend to be somewhat lower (e.g. ${ }^{3} \mathrm{H}=1 \times 10^{6}$ to $1 \times 10^{7} \mathrm{pCi} / \mathrm{L}$, Crow, 1976; Bryant, 1992) due to groundwater dilution.

The natural ${ }^{3} \mathrm{H}$ abundance $\left(\mathrm{T}_{1 / 2}=12.4\right.$ years) sets an important limit on the age of the groundwater. The groundwater from UE-1-q has a ${ }^{3} \mathrm{H}$ concentration below the detection limit $(1.0 \mathrm{pCi} / \mathrm{L})$ that corresponds to a residence age of greater than 50 years.

The ${ }^{3} \mathrm{H}$ analysis completed at LLNL is determined using the ${ }^{3} \mathrm{He}$ accumulation technique (Surano et al., 1992). In this method, all the ${ }^{3} \mathrm{He}$ initially present in the sample is removed and the ${ }^{3} \mathrm{H}$ is allowed to decay to its daughter product ${ }^{3} \mathrm{He}$ for a known length of time, and to accumulate to a measurable amount of ${ }^{3} \mathrm{He}$. After about $6($ ) days, the 
accumulated ${ }^{3} \mathrm{He}$ is analyzed by high sensitive mass spectrometry (detection limit $=10^{4}$ atoms $\left.{ }^{3} \mathrm{He}\right)$.

Except for tritium and uranium, the activity levels of the other radionuclides measured in the water from UE-1-q (Table 1) fall below their detection limits, and do not occur at unnatural levels. Any future potential source of radionuclides in groundwater from UE-1-q would be from the closest nuclear cavity site approximately $1.5 \mathrm{~km}$ to the west and down gradient of the regional groundwater flow from UE-1-q. Unusually high flow rates $(>50 \mathrm{~m} / \mathrm{yr})$ or channelized flow would have been necessary for any radionuclides to migrate to the UE- $1-\mathrm{q}$ area by the present time.

\section{Natural Isotopic Signatures}

Carbon-14 - Carbon-14 is a commonly used age discriminator of groundwater (see Mazor, 1991 for review) and provides in many cases the most reliable chronometer for groundwater flow. The ${ }^{14} \mathrm{C}$ is produced by cosmic ray interaction with nitrogen $\left({ }^{14} \mathrm{~N}+\mathrm{n}\right.$ $={ }^{14} \mathrm{C}+\mathrm{p}$ ) in the upper atmosphere. The ${ }^{14} \mathrm{C}$ derived from atmospheric fallout is incorporated into the shallow groundwater, dissolved into inorganic (as bicarbonate) and organic phases, and decays from an initial concentration that is assumed to be characteristic of the groundwater's recharge area. The ${ }^{14} \mathrm{C}$ abundance to total carbon in a groundwater mass at any given time is a function of its decay rate $\left(T_{1 / 2}=5730 \mathrm{yrs}\right.$.). In addition, the dissolved ${ }^{14} \mathrm{C}$ to total carbon can also depend on water-rock exchange with ${ }^{14} \mathrm{C}$ depleted carbon-bearing lithologies. This is particularly important for the NTS where the Paleozoic carbonates present a large source of "dead" dissolved inorganic carbon in the vadose and saturated zones. Carbon-13 analyses of the groundwater have been used to attempt to delineate the different carbon sources at the NTS (Grove et al., 1969; Spencer, 199()). Dissolved inorganic ca ron from the root zone of the recharge area usually has a lower ${ }^{13} \mathrm{C}$ abundance $(-25.0$ to $-12.0 \%$, normalized to PDB standard) relative to the Paleozoic carbonates $(-2.0)(0+2.0 \%$ \% $)$. A mass halance calculation 
between the two carbon sources has been proposed for the NTS (Grove et al., 1969; Spencer, 1990) which provides a correction factor that is a ${ }^{13} \mathrm{C}$ dependent ratio such that:

$$
{ }^{14} C_{\text {correct }}=\left(\frac{\delta^{13} C_{\text {soil }}-\delta^{13} C_{\text {carbonate }}}{\delta^{13} C_{\text {measured }}-\delta^{13} C_{\text {carbonate }}}\right){ }^{14} C_{\text {measured }}
$$

where $\delta^{13} \mathrm{C}=\left(\mathrm{R}_{\mathrm{sa}} / \mathrm{R}_{\mathrm{st}}-1\right) 1000$, and $\mathrm{R}$ is the ${ }^{13} \mathrm{C} /{ }^{12} \mathrm{C}$ ratio of the sample and a standard respectively. For this equation to be valid, a uniform $\delta^{13} C_{\text {soil }}$ value is required. Spencer (1990) suggested that most ${ }^{13} \mathrm{C}$ values for soil carbon at the NTS was $-12.0 \%$.

Figure 2 is a ${ }^{13} \mathrm{C}-{ }^{14} \mathrm{C}$ compilation of many springs and groundwaters at the NTS. For the equation above to be true in all cases, all the ${ }^{13} \mathrm{C}-{ }^{14} \mathrm{C}$ values of groundwaters in Fig 2 must have originated at a common point where the ${ }^{14} \mathrm{C}(\mathrm{pmc}) \sim 100$, and the $\delta^{13} \mathrm{C} \sim$ $-12 \%$. From that common point, the ${ }^{13} \mathrm{C}$ and ${ }^{14} \mathrm{C}$ values change within a triangular region confined by a line extending from the originating point to $\delta^{13} \mathrm{C}=0 \%$ and ${ }^{14} \mathrm{C}=0$. This line defines the change in ${ }^{14} \mathrm{C}$ abundance of a groundwater from dissolution of Paleozoic carbonate with no associated radioactive decay of the ${ }^{14} \mathrm{C}$, and defines an upper graphical limit on the position of the data points. This limiting trend is suggested by the data in Fig 2. Older groundwaters $(<50 \mathrm{pmc})$ with low ${ }^{13} \mathrm{C}$ values suggest that little water-rock interaction has occurred with carbonate lithologies as might be expected, for instance, in the Pahute Mesa area. Younger apparent-aged groundwaters in Fig. 2 with higher ${ }^{13} \mathrm{C}$ values suggest a significant interaction with the Paleozoic carbonates.

Two uncertainties exists in this simple correction model for the ${ }^{14} \mathrm{C}$ ages: 1 ) the model assumes that all ${ }^{13} \mathrm{C}$ values originate at a common value, where the ${ }^{13} \mathrm{C}$ in groundwater within the soil root zone actually may be quite variable due to different plant types and densities or lithological variability, 2) the model also assumes that exchange with the Paleozoic carbonates is simple dissolution of "dead" carbonate that contributes to the total inorganic carbon in the groundwater. Reprecipitation and redissolution of the 
bicarbonate probably is the main control on the bicarbonate concentration and hence ${ }^{13} \mathrm{C}$ values of the groundwater is not likely to be linearly related to its ${ }^{14} \mathrm{C}$ content.

Groundwaters with a substantial reservoir age probably experience carbon exchange and isotopic equilibration with the Paleozoic carbonates, and the groundwaters in Fig. 2 with old apparent ${ }^{14} \mathrm{C}$ ages and with the highest ${ }^{13} \mathrm{C}$ values (e.g. ER-6-1) suggests that the ${ }^{13} \mathrm{C}$ isotopic exchange between the bicarbonate in the groundwater and the Paleozoic carbonates is neal complete, and that the dissolved bicarbonate reflects the dominant carbon reservoir.

Groundwater from UE-1-q has an uncorrected ${ }^{14} \mathrm{C}$ age of 20,650 years and a $\delta^{13} \mathrm{C}$ value of $-2.3 \%$. The ${ }^{13} \mathrm{C}$ content of groundwater from UE-1-q is very close to that expected for the Paleozoic carbonates and a ${ }^{13} \mathrm{C}$ age correction applied to UE-1-q would yield a ${ }^{14} \mathrm{C}$ age of approximately 7600 years. Since UE-1-q is completed in the Paleozoic carbonates, extensive isotopic exchange of ${ }^{13} \mathrm{C}$ between the groundwater and the carbonates is plausible, and therefore the corrected ${ }^{14} \mathrm{C}$ age would represent a minimum residence time for the groundwater. The actual age of the groundwater in UE-1-q lies between 20,650 and 7600 years.

The uncorrected ${ }^{14} \mathrm{C}$ age of the groundwater from UE-1-q is considered a maximum possible age, and more data and further investigation is needed to determine a ${ }^{14} \mathrm{C}$ correction model that suitably considers: 1) ${ }^{13} \mathrm{C}$ fractionation during carbonate exchange in open and closed systems, and 2) the spatial and temporal variability of initial ${ }^{13} \mathrm{C}$ and ${ }^{14} \mathrm{C}$ values of the recharge water. The uncorrected age for UE-1-q groundwater is intermediate to the apparent ${ }^{14} \mathrm{C}$ ages derived for TW-2 (15,680 yrs; Grove et al., 1969; well is now called Well-2) in northern Yucca Flat, well C-1 $(28,990$ yrs) and well ER-6-1 $(31,140 \mathrm{yrs}$; accompanying report) in the southeastern portion of Yucca Flat. Gradients in the water lable surface are highest in northern Yucca Flat and lowest in the area of ER6-1 of southwestern Yucea Flat (Winograd et al., 1975), while the water table gradient is intermediate in the area of UE-1-4. Winograd et al. (1975) surmised that the groundwater 
beneath Yuxca Flat was not part of a regional flow system, and that recharge rates were controlled by the local groundwater table gradients. The relative ${ }^{14} \mathrm{C}$ ages of UE-1-q, TW-2, C-1, and ER-6-1 suggest that the water table elevations reflect the groundwater ages in Yucca Flat, such that higher water tables in high water table gradient areas reflect younger recharge. The absolute ${ }^{14} \mathrm{C}$ ages at this time are still uncertain, although the apparent ${ }^{14} \mathrm{C}$ age differences of groundwater from the wells mentioned above appear to be systematic in this hydrologic framework.

Chlorine-36 - Several studies have attempted to exploit the natural radioactive decay rates of $36 \mathrm{Cl}\left(\mathrm{T}_{1 / 2}=301,000 \mathrm{yrs}\right)$ for age dating of old groundwater (see Bentley, 1986). In principal, the ${ }^{36} \mathrm{Cl}$ abundance in groundwater decays from an initial activity that is characteristic of the recharge area. Since chloride is a conservative soluble species in an aqueous environment, the ${ }^{36} \mathrm{Cl}$ abundance should not be affected by aqueous geochemical reactions. The natural decay in $36 \mathrm{Cl}$, though, may be partially countered by simultaneous production of $36 \mathrm{Cl}$ in the subsurface due to ncutron flux from other radioactive elements (e.g. uranium). Both the initial ${ }^{36} \mathrm{Cl}$ abundance from the recharge area and subsurface production have been considered in age determination of groundwater (Bentley, 1986).

Bentley et al. (1986) first applied these methods to the Great Artesian Basin in Australia, where they showed systematic age increases (from $<100,000$ to $1,200,000$ yrs) with increasing depth along a Jurassic sandstone aquifer. These ages agreed with hydrodynamically calculated ages. Phillips et al. (1986) attempted to apply the same principals to the Milk River aquifer in Alberta, Canada, where non-systematic $36 \mathrm{Cl}$ atom abundance trends were interpreted to be inlluenced by ion filtration of chloride in the subsurface. Based on this assumption, Phillips et al. (1986) calculated ages from $5(X),()(K)$ to 2,(K)(0,0()() yrs for the groundwater. Subsequent works (Hendry and Schwartz, 1988; Nolte et al., 1991; Fahryka-Martin et al., 1991) have demonstrated that groundwater 
dispersion and chloride diffusion are probably controlling the $36 \mathrm{Cl}$ abundances in the Milk River aquifer, and maximum ages may only be $1,(0)(),()())$ yrs, although these ages are still a factor of two greater than the calculated hydrodynamic ages.

Norris et al. (1987) and Phillips et al. (1988) have both shown that chloride mobility (and hence ${ }^{36} \mathrm{Cl}$ mobility) in the vadose zone is much slower than water, due to the simple fact that water is able to transport as a liquid and vapor, where chloride movement is limited only to the aqueous phase. The time lag between chloride and water movement in the unsaturated zone may be significant in terms of groundwater age dating with ${ }^{36} \mathrm{Cl}$, particularly at the NTS where the vadose zone can be very thick. The chloride distribution and mobility in the vadose zone is also spatially heterogeneous (Norris et al., 1987) probably due to differing infiltration rates.

Current work at LLNL on the Dakota aquifer of Kansas shows thit large variations in ${ }^{36} \mathrm{Cl}$ age determinations $(2700$ to $1,300,000 \mathrm{yrs})$ for the groundwater contrasts with the relative young ages for the groundwater determined from ${ }^{14} \mathrm{C}$ analyses ( 1800 to $50,000 \mathrm{yrs})$. It is probable that the age discrepancy is due in part to the nonconservative behavior of chloride in the vadose zone. Chloride with a low ${ }^{36} \mathrm{Cl}$ abundance dissolved from the host rock may also have an influence on the ages, particularly since this chloride has a marine source and a complex history.

A similar condition exists in the NTS groundwaters. Table 2 shows ${ }^{36} \mathrm{Cl}$ data of groundwater from wells sampled and analyzed by LLNL from the NTS (HRMP 1992) and from the Faultless site in central Nevada. Ages have been calculated from the $36 \mathrm{Cl}$ abundances, assuming that the initial ${ }^{36} \mathrm{Cl}$ concentration is $\sim 40 \times 10^{7}$ atoms (this value was chosen to allow an approximately equal age to the ${ }^{14} \mathrm{C}$ age of UE-1-a, see Table 2 ) as well as from the ${ }^{14} \mathrm{C}$ ahundances. It is apparent that the large variations in ${ }^{36} \mathrm{Cl}$ ages are contrary to typical ${ }^{14} \mathrm{C}$ ages seen in NTS groundwater (e.g. Grove et al., 1969). It is clear from this data that the ${ }^{36} \mathrm{Cl}$ abundance is controlled by more than just simple radioactive decay. Possibly the slow chloride mobility in the thick vadose zone at the NTS 
significantly affects the ${ }^{36} \mathrm{Cl}$ abundances in the saturated zone of the groundwater, such that the rate of water and water vapor movement through the vadose zone to the saturated zone far exceeds that for aqueous shloride. The rate of chloride movement through the vadose zone will also be heterogeneous from one location to the next due to differences in permeability and infiltration rates and surface precipitation.

More data and further investigation is needed to test the hypothesis that chloride mobility in the vadose zone influences $36 \mathrm{Cl}$ age determinations of groundwater. Other equally important considerations are identifying all chloride sources as well as quantifying subsurface production of $36 \mathrm{Cl}$, although the effects of these latter two elements are probably minor for the NTS.

Strontium lsotopes - Strontium-87 is a stable daughter product of ${ }^{87} \mathrm{Rb}$ decay. Because ${ }^{87} \mathrm{Rb}$ decays very slowly (half-life $=4.8 \times 10^{10} \mathrm{yrs}$ ), the ${ }^{87} \mathrm{Sr} / 86 \mathrm{Sr}$ ratio of a groundwater's host rock is stable within the time-frame of groundwater flow rates. The ${ }^{87} \mathrm{Sr} / 86 \mathrm{Sr}$ ratin of a rock will be reflected in the ${ }^{87} \mathrm{Sr} / 86 \mathrm{Sr}$ ratio of the groundwater that resides within that rock when the groundwater and rock are in isotopic equilibrium.

Peterman et al. (1992) has presented the most comprehensive data set for ${ }^{87} \mathrm{Sr} / 86 \mathrm{Sr}$ ratios in southwestern Nevada groundwater thus far. They noted that the $\delta^{87} \mathrm{Sr}$ values (where $\left.\delta^{87} \mathrm{Sr}=\left({ }^{87} \mathrm{Sr} / 86 \mathrm{Sr} / 0.70920-1\right) 1000\right)$ for springs and wells depended on the $\mathrm{Ca} / \mathrm{Na}$ ratio of the groundwater (Figure 3). The authors suggest that a higher proportion of $\mathrm{Na}$ in a groundwater at the NTS would indicate an influence from the volcanic tuff lithology, whereas a higher calcium proportion would reflect the carbonate lithology.

The increases in Sr concentration of NTS groundwaters are approximately proportional to increases in $\mathrm{Ca} / \mathrm{Na}$ ratios (Figure 4). A comparison of figures 3 and 4 suggests that the $\mathrm{Ca} / \mathrm{Na}$ ratio generally reflects the Sr concentrations, and that the $\mathrm{Ca} / \mathrm{Na}$ 
ratio in Fig. 3 approximately mimics a $\mathrm{Sr}$ axis of a hyperbolic mixing diagram between dissolved $\mathrm{Sr}$ and its $\delta^{87} \mathrm{Sr}$ signature.

Figure 3 suggests that groundwaters with low $\mathrm{Ca} / \mathrm{Na}$ ratios tend to have more radiogenic signatures, whereas higher $\mathrm{Ca} / \mathrm{Na}$ ratios tend to reflect near seawater values. It is speculated that the Paleozoic carbonates would typically have near seawater $\delta^{87} \mathrm{Sr}$ values as well as higher Sr concentrations, whereas the volcanic tuffs typically have more radiogenic values and much lower $\mathrm{Sr}$ concentrations (Peterman et al., 1992). Direct measurements of the Paleozoic carbonate rocks from UE-1-q are unavailable at this time. According to the model suggested by Peterman et al. (1992), since the $\delta^{87} \mathrm{Sr}$ value in the groundwater from UE-1-q is more radiogenic and has a low $\mathrm{Ca} / \mathrm{Na}$ ratio, it is suggested that the groundwater has a significant component derived from the volcanic tuffs. This is contrary to the expected groundwater origin, since the well is completed in the carbonate zone.

Peterman et al. (1992) indicated, however, that many tuffs have high $\delta^{87} \mathrm{Sr}$ values, but noted that isotopic zonation of volcanic tuffs did occur around Yucca Mt. $\left(\delta^{87} \mathrm{Sr}=\right.$ 0.0 to 9.63 ). Isotopic heterogeneity of the rock may be significant and could locally control the isotopic ratio of the groundwater as suggested by other groundwater measurements in the Yucca Mountain region (Stuckless et al., 1991). Likewise, the Sr concentration in the lithology may vary locally as well, and further data and investigation is needed. The ${ }^{87} \mathrm{Sr}$ values may be variable in the Paleozoic carbonates particularly if a Rb-rich mineral phase coexists with the carbonates. Strontium isotope measurements of the actual carbonates recovered from UE-1-q is needed.

Uranium Isotopes - The secular equilibrium of natural radioactive decay established between ${ }^{234} \mathrm{U}$ and ${ }^{238} \mathrm{U}$ have been used to estimate groundwater ages (Davis and Murphy, 1986). The activity ratio of ${ }^{234} \mathrm{U} / 238 \mathrm{U}$ should equal 1.0 when the two isotopes have equal solubility in the groundwater. Typically, the activity ratios are greater than 
1.0 in many groundwaters due to greater solubility from crystal lattice defects created during radioactive decay that has allowed preferential dissolution of $234 \mathrm{U}$ from the rock.

Osmond and Cowart (1982) have presented the most comprehensive data base of ${ }^{234} U / 238 U$ for groundwater and springs in southwestern Nevada (Figure 5). Because most groundwaters in southwestern Nevada are found to be oxidized, Osmond and Cowart (1982) suggested that the uranium can be considered a conservative aqueous species. They suggested that the ${ }^{234} U$ excess (where the ${ }^{234} U$ excess $=$ (activity ratio 1)[U]) of the groundwaters in the carbonate aquifer is controlled by mixing between the recharge areas of the Spring Mountains and the Pahranagat Valley, where the carbonate lithology is exposed. From their data, they further suggested that the Indian Springs area and the Yucca Flat carbonate aquifer have little contribution to the Ash Meadows discharge (Figure 5).

GCP wells UE-1-q and ER-6-1 are also plotted in Figure 5. As can be seen, the GCP wells do not plot within the mixing triangle suggested by Osmond and Cowart (1982), but rather have a much higher ${ }^{234} \mathrm{U}$ excess. This suggests that the uranium concentrations and the ${ }^{234} \mathrm{U} / 238 \mathrm{U}$ activity ratio may have a more local control in Yucca Flat and do not suitably compare to a regional interpretation such as Figure 5. Possible controls on the aqueous uranium may be due to a heterogeneous distribution of uranium in the rock. It may also be possible that a significant variability in oxidizing conditions in the subsurface exists and limits uranium mobility. Further investigation is needed at the NTS to resolve the uranium geochemical systematics of groundwater and its interaction with the subsurface lithology. Furthermore, ${ }^{234} \mathrm{U} / 238 \mathrm{U}$ measurements of recovered core from UE-1-q would be beneficial.

Noble Gases - The non-radiogenic noble gas concentrations in groundwater offer a variety of important information on the source and age of a groundwater mass. In particular, Mazor (1972) showed that the temperature dependency of argon, krypton, 
xenon, and neon solubility in groundwater could be exploited to determine recharge temperatures by accurately measuring the relative abundances of the noble gases dissolved in the groundwater.

The noble gas abundance in the groundwater from UE-1-q suggests a recharge temperature of $16 \pm 1^{\circ} \mathrm{C}$. This temperature is consistent with current mean annual air temperatures measured within this region of the NTS (Winograd et al., 1975; Lyles and Mihevc, 1992). Based on an altitude calculation from the noble gas data, a $1500 \pm 300 \mathrm{~m}$ elevation is determined. Yucca Flat elevation ranges approximately from $1200 \mathrm{~m}$ at the valley floor to $1800 \mathrm{~m}$ for the adjacent hills, and this elevation range is entirely consistent with the noble gas calculations. In general, the noble gas data are consistent with the idea that the recharge is of local origin agreeing with the ${ }^{14} \mathrm{C}$ results and arguments of Winograd et al. (1975).

Because of the long range transport of ${ }^{4} \mathrm{He}$ in the crust, it is difficult to use ${ }^{4} \mathrm{He}$ accumulation as a precise groundwater chronometer. Since the aquifer is a trap for ${ }^{4} \mathrm{He}$, however, high concentrations of ${ }^{4} \mathrm{He}$ generally indicate long residence ages for the groundwater. A simple model can be used to estimated the residence age. We take a uniform crustal flux of ${ }^{4} \mathrm{He}$ to be $3 \times 10^{6}$ atoms ${ }^{4} \mathrm{He} / \mathrm{cm}^{2} \mathrm{sec}$ (e.g. Torgerson and Clarke, 1985 and O'Nions and Oxburgh, 1983), and given the ${ }^{4} \mathrm{He}$ flux into the water and the volume of the water we can calculate the rate at which the ${ }^{4} \mathrm{He}$ concentration should increase or:

$$
{ }^{4} \mathrm{He}=\left(\frac{(\text { Flux })(\text { Residenceage })}{(\text { Aquiferthickness })(\text { Porosity })}\right) .
$$

The measured radiogenic ${ }^{4} \mathrm{He}$ concentration is about $10^{12}$ atoms $/ \mathrm{ml}$ for UE-1-q. If we choose an aquifer thickness of $10^{3} \mathrm{~m}$ and a porosity of $20 \%$, then we calculate an age of approximately 200 years. In general, the water is old but the ${ }^{4} \mathrm{He}$ data gives an age a 
factor of 100 less than the apparent ${ }^{14} \mathrm{C}$ age. The lower apparent ${ }^{4} \mathrm{He}$ age may be due to a reduced regional tlux of ${ }^{4} \mathrm{He}$ into the aquifer beneath the Nevada Test Site. This model also assumes that no ${ }^{4} \mathrm{He}$ loss from the aquifer has occurred. The ${ }^{4} \mathrm{He}$ age is very uncertain at this time but may be calibrated against the ${ }^{14} \mathrm{C}$ ages as the GCP data base grows.

\section{CONCLUSION}

No evidence exists in the groundwater radiochemistry data from UE-1-q that anthropogenic contamination resides in the water bearing zone penetrated by this observation well. The levels of all radionuclides measured, including ${ }^{3} \mathrm{H}$, occur below their respective detection limits specified in this report.

Natural isotopic abundances in the groundwater from UE-1-q give an indication of the source and age of the groundwater. For instance, noble gas data indicates that the groundwater mass was recharged at a temperature and elevation comparable to modern mean temperatures and altitudes in the Yucca Flat area.

The ${ }^{14} \mathrm{C}$ abundance in the groundwater from UE-1-q suggests a maximum age of approximately 21,000 years. The ${ }^{13} \mathrm{C}$ correction formulas previously developed for the NTS are probably over-simplified and more work is needed to develop a more detailed correction model. The ${ }^{4} \mathrm{He}$ accumulated in groundwaters from UE-1-q yields an age younger than the apparent ${ }^{14} \mathrm{C}$ ages, although the ${ }^{4} \mathrm{He}$ age is very uncertain at this time. As more simultaneous ${ }^{14} \mathrm{C}$ and ${ }^{4} \mathrm{He}$ data are collected, the calibration of the ${ }^{4} \mathrm{He}$ dating system will improve.

According to predictions from previous models, the ${ }^{87} \mathrm{Sr} /{ }^{86} \mathrm{Sr}$ signature in UE-1-q groundwater suggests that a significant component of the groundwater is derived from the overlying volcanic tuffs, although this result is contrary to expectation. Direct ${ }^{87} \mathrm{Sr} / 86 \mathrm{Sr}$ measurements of the carbonate lithology is needed to help resolve this discrepancy. 
At this time ${ }^{36} \mathrm{Cl}$ does not constitute a reliable chronometer for groundwater at the NTS for reasons outlined above. Further investigation of the different sources of $36 \mathrm{Cl}$ and vadose mobility of chloride is warranted.

In addition, ${ }^{234} \mathrm{U} / 238 \mathrm{U}$ systematics of the groundwater at the NTS are complex and may have been previously over-simplified, and further work is needed.

Through the efforts of the GCP, many of the uncertainties in the natural isotopic studies at the NTS will be resolved as more wells are drilled and the data base grows. Statistically representative data are crucial to the determination of the systematic behavior of these isotopic species. Comprehension of the systematic behavior of these isotopic systems in groundwater at the NTS is needed to accurately interpret the source, age, and migration of the groundwater. 


\section{REFERENCES}

Bentley, H.W., 1986, Chlorine-36 in the terrestrial environment, in Fritz, P., Fontes, J. Ch., eds. Handbook of Environmental Isotope Geochemistry. p. 427-48().

Bentley, H.W., Phillips, F.M., Davis, S.N., Habermehl, M.A., Airey, P.L., Calf, G.E., Elmore, D., Gove, H.E., Torgersen, T., 1986, Chlorine-36 dating of very old groundwater: 1. The Great Artesian Basin, Australia. Water Resour. Res., 22, p. 1991-20()1.

Borg, I.Y., Stone, R., Levy, H.B., Ramspott, L.D., 1976, Information pertinent to the migration of radionuclides in groundwater at the Nevada Test Site. UCRL-52078, LLNL, 216 pgs.

Bryant, E.A., 1992, The Cambric migration experiment. LA-12335-MS, LANL, 37 pgs.

Claassen, H.C., 1973, Water quality and physical characteristics of Nevada Test Site water-supply wells. USGS-474-158, 145 pgs.

Crow, N.B., 1976, First observations of tritium in groundwater outside chimneys of underground nuclear explosions, Yucca Flat, Nevada Test Site. UCRL-52073, LLNL, 36 pgs.

Davis, S.N. and Murphy, E., 1986, Dating Groundwater and the Evaluation of Repositories for Radioactive Waste. NUREG/CR-4912, University of Arizona. $181 \mathrm{pgs}$. 
Elmore, D., et al., 1979, Analysis of ${ }^{36} \mathrm{Cl}$ in environmental water samples using an electrostatic accelerator. Nature, 277, p. 22-25.

Fabryka-Martin, J., Whittemore, D.O., Davis, S.N., Kubik, P.W., Sharma, P., 1991, Geochemistry of halogens in the Milk River aquifer, Alberta, Canada. Applied Geochem., 6, p. 447-464.

Failor, R.A., Beiriger, J., Rego, J.H., Buddemeier, R.W., Marsh, K.V., 1988, Calibration and application of Marinelli beakers. UCRL-53779, LLNL, p. 32-34.

Goldherg, E.D., Minoru, K., Schmitt, R.A., Smith, R.H., 1963, Rare-earth distributions in the marine environment. Jour. Geophy. Res., 68, p. $4209-4217$.

Grove, D.B., Rubin, M., Hanshaw, B.B., Beetem, W.A., 1969, Carbon-14 dates of groundwater from a Paleozoic carbonate aquifer, south-central Nevada. U.S. Geol. Survey Prof. Paper 650)-C, p. C215-C218.

Gunnink, R. and Niday, J.B., 1972, Computerized quantitative analysis by gamma-ray spectrometry. UCRL-51061, LLNL.

Hendry, M.J. and Schwartz, F.W., An alternative view on the origin of chemical and isotopic patterns in groundwater from the Milk River aquifer, Canada. Water Resour. Res., 24, p. 1747-1763.

Horwitz, E.P., Dietz, M.L., Fisher, D.E., 1991, Separation and preconcentration of strontium from hiological, environmental, and nuclear waste samples by extraction chromatography using a crown ether. Anal. Chem., 63, 522-525. 
Lyles, B.F. and Miheve, T.M., 1992, NTS groundwater recharge study, FY 1992. Desert Research Institute. 40 pgs.

Mazor, E., 1991, Applied Chemical and Isotopic Groundwater Hydrology. Halsted Press: New York, 274 pgs.

Mazor, E., 1972, Paleotemperatures and other hydrological parameters deduced from noble gases dissolved in groundwater; Jordan Rift Valley, Israel. Geochim. Cosmochim. Acta, 36, p. 1321-1336.

Nolte, E., Krauthan, P., Korschinek, G., Maloszewski, P., Fritz, P., Wolf, M., 1991, Meusurements and interpretations of ${ }^{36} \mathrm{Cl}$ in groundwater, Milk River aquifer, Albert, Canada. Applied Geochem., 6, 435-445.

Norris, A.E., Wolfsherg, K., Gifford, S.K., Bentley, H.W., Elmore, D., 1987, Infiltration at Yucca Mountain, Nevada, traced by ${ }^{36} \mathrm{Cl}$. Nuclear Instr. Methods. Phys. Res., B29, p. 376-379.

O'Nions, R. K. and Oxburgh, E.R., 1983, Heat and helium in the earth: Nature, 306, p. $429-431$.

Osmond, J.K. and Cowart, J.B., Groundwater. in Ivanovich, M. und Harmon, R.S., eds. Uranium Series Disequilibrium: Applications to Environmental Problems. Clarendon Press: ()xford. p. 2012-245. 
Peterman, Z.E., Stuckless, J.S., Muhau, S.A., Marshall, B.D., Gutentag, E.D., Downey, J.S., 1992, Strontium isotope characterization of the Ash Meadows groundwater system, southern Nevada, USA. in Kharaka, Y.K., Maest, A.S., eds. Proceedings of the 7 th International Symposium on Water-Rock Interaction-WRI-7, Park City, Utah, p. 825-829.

Phillips, F.M., Bentley, H.W., Davis, S.N., Elmore, D., Swanick, G.B., 1986, Chlorine-36 dating of very old groundwater: 2. Milk River aquifer, Alberta, Canada. Water Resour. Res., 22, p. 2()(13-2016.

Phillips, F.M., Mattick, J.L., Duval, T.A., Elmore, D., Kubik, P.W., 1988, Chlorine-36 and tritium from nuclear weapons fallout as tracers for long-term liquid and vapor movement in deserts soils. Water Resour. Res., 24, p. 1877-1891.

Poreda, R.J., Cerling, T.E., Salomon, D.K., 1988, Tritium and helium isotopes as hydrologic tracers in a shallow unconfined aquifer. Jour. Hydrol., 103, p. 1-9.

Silva, R.J., Evans, R., Rego, J.H., Buddemeier, R.W., 1986, Technetium analyses in the radionuclide migration project. Nuclear Chemistry Division FY86 Annual Report, LLNL, p. 14-16.

Spencer, E.B., A radiocarhon study of groundwater in the western Nevada Test Site and vicinity. Master's Thesis, Universily of Nevada, Reno. 124 pgs.

Stuckless, J.S., Peterman, Z.E., Muhs, D.R., 1991, U and Sr isotopes in groundwater and calcite, Yucea Mountain, Nevada: Evidence against upwelling water. Science, 2.54, p. $5.51-.554$. 
Stuiver, M. and Polach, H.A., 1977, Reporting of ${ }^{14} \mathrm{C}$ data. Radiocarbon, 19, p. 355-363.

Surano, K.A., Hudson, G.B., Failor, R.A., Sims, J.M., Holland, R.C., MacLcan, S.C., Garrison, J.C., 1992, Helium-3 mass spectrometry for low -level tritium analysis of environmental samples. Jour. Radioanal. Nuclear Chem. Art., 161, p. 443-453.

Torgerson, T. and Clarke, W. B., 1985, Helium accumulation in groundwater, I: An evaluation of the sources and the continental flux of crustal ${ }^{4} \mathrm{He}$ in the Great Artesian Basin, Australia. Geochimica st Cosmochimica Acta, 49, p. 1211 1218.

Winograd, I.J., Thordarson, W., 1975, Hydrogeologic and hydrochemical framework, south-central Great Basin, Nevada-California, with special reference to the Nevada Test Site. U.S. Geological Survey Professional Paper 712-C. 126 pgs. 


\section{FIGURE CAP'TIONS}

Figure 1. Location of GCP well UE-1-q within Nevada Test Area 1.

Figure 2. Carbon-13 and ${ }^{14} \mathrm{C}$ data from the Nevada Test Site with GCP groundwaters indicated. The distribution of the data approximately reflects the theoretical behavior expected according to the ${ }^{13} \mathrm{C}$ correction equation presented in the text. The underlying assumption is that ${ }^{13} \mathrm{C}$ is uniform in the recharge waters, a condition that needs further investigation. In addition, ${ }^{13} \mathrm{C}$ equilibration with the host Paleozoic carbonates is evident particularly in GCP groundwaters UE-1-q and ER-6-1. The ${ }^{13} \mathrm{C}$ equilibration with the Paleozoic carbonates will yield ahnormally young groundwater ages using the ${ }^{13} \mathrm{C}$ correction formula.

Figure 3. Plot from Peterman et al. (1992) showing that more radiogenic $8^{87} \mathrm{Sr}$ values correspond to greater proportions of $\mathrm{Na}$ over $\mathrm{Ca}$ in the groundwater. Enrichment of $\mathrm{Sr}$ concentrations in groundwater tend to follow Ca enrichment (Figure 4) and therefore, the plot can be viewed as a general mixing diagram between $8^{87} \mathrm{Sr}$ and $\mathrm{Sr}$. Peterman et al. (1992) suggested that higher $\mathrm{Ca} / \mathrm{Na}$ ratios correspond to greater influence of the Paleozoic carbonates on the groundwater genchemistry, where lower $\mathrm{Ca} / \mathrm{Na}$ ratios reflect the volcanic tuffs. This suggests that the GCP well UE-1-q has a significant proportion of groundwater derived from the volcanic tuff's even though the intake area is completed in the Paleozoic carbonates. This is contrary to expectation and direct measurements of the recovered core is needed.

Figure 4. Sr, Ca, and $\mathrm{Na}$ relationship for the water supply wells at the Nevada Test Site (Claassen, 1973) show a positive relationship hetween the $\mathrm{Sr}$ and the $\mathrm{Ca} / \mathrm{Na}$ ratio that indicates most Sr and Ca have sources in the Paleozoic carbonates. This plot suggests that $\mathrm{Sr}$ can be generally substituted for $\mathrm{Ca} / \mathrm{Na}$ ratio values in Figure 3, and that Figure 3 
represent a general mixing diagram. Note that the $\mathrm{Ca} / \mathrm{Na}$ ratios for the NTS wells are up to I(0) times less than values determined for springs by Peterman et al. (1992) although the authors found comparable ratios for NTS well samples.

Figure 5. The ${ }^{234} \mathrm{U}$-excess for southwestern Nevada groundwater is compared to their uranium concentrations (after Osmond and Cowart, 1982). Osmond and Cowart (1982) suggested that the oxidized waters in this region allow conservative treatment of the uranium mobility in the groundwater. They suggested that the data in this figure represents mixing of different water masses in the hypothesized regional flow system for the region. Well UE-1-q is from Yucca Flat (considered separate from the regional flow) and has a higher ${ }^{234} \mathrm{U}$-excess than those within the mixing diagram. HS=Hi Ko Spr., $C S=$ Crystal Spr., PWS=Pederson Warm Spr., AS=Ash Spr., DH=Devil's Hole, AT=Armagosa Test Well, KS=King Spr., CP=Crystal Pool, BS=Big Spr., RS=Rogers Spr., FBSW=Fairbanks Spr. southwest, FBNE=Fairhanmks Spr. northeast, IS=Indian Spr., ARMY=Army Well \#1, CC=Cold Spr., TS=Trout Spr., TrS=Travertine Spr., TxS=Texas Spr., NS=Nevares Spr., WJF=Jackass Flats welded tuff aquifer, WFF=Frenchman Flats welded tuff aquifer, $A F F=$ Frenchman Flats alluvial aquifer, $Y F=Y u c c a$ Flats, Paleozoic carbonate aquifer. 


\section{APPENDIX 1}

Tritium Monitoring - Field monitoring of tritium was conducted routinely by ReeCo and DRI and supervised by LLNL at the Nevada Test Site. All field monitored samples show ${ }^{3} \mathrm{H}$ levels below detectability. The sample at the water table (487 mbs) was suspiciously high ( 10 count/min above hackground) but less than one-half the drinking water standard. The sample was shaken and re-measured and was found to be significantly reduced. 


\section{APPENDIX 2}

Sampling and Analytical Techniques - Samples for isotope analysis were collected on July 10, 1992 following a 72 hour pump test conducted by Desert Research Institute. All sample containers were filled along the discharge path from the well pump. Samples for the ${ }^{3} \mathrm{H},{ }^{60} \mathrm{Co},{ }^{125} \mathrm{Sb},{ }^{137} \mathrm{Cs}$, and ${ }^{36} \mathrm{Cl}$ analysis were collected unfiltered and unacidified in 1 liter 1 -Chem polyethylene bottles pre-cleaned by the bottle manufacturer. The ${ }^{90} \mathrm{Tc}$ sample was collected unfiltered and unacidified in a similar 4 liter I-Chem bottle. Samples for ${ }^{90} \mathrm{Sr},{ }^{87} \mathrm{Sr} /{ }^{86} \mathrm{Sr}$, and ${ }^{234} \mathrm{U} / 238 \mathrm{U}$ were filtered with a $0.45 \mu$ filter pack, acidified to a $\mathrm{pH} 2$, and stored in acid-leached 1 liter 1 -Chem polyethylene bottles. The ${ }^{14} \mathrm{C}$ sample was collected in a pre-leached glass bottle by creating a non-turbulent overflow of the bottle to purge any atmospheric mixture. The ${ }^{14} \mathrm{C}$ sample was poisoned with $<0.5 \mathrm{ml} \mathrm{HgCl} 2$ solution, and the bottle was capped with an air-tight seal. The ${ }^{3} \mathrm{H}$ ${ }^{3}$ He sample was filled by a slow laminar flow into a glass bottle and sealed with an airtight cap. The ${ }^{85} \mathrm{Kr}$ sample was collected in a stainless steel vessel with a high-pressure valve at each of the two ends. The noble gas sample was similarly collected in a $3 / 8$ " copper tube mounted to a pinch clamp assembly. Both were collected by creating a laminar through-flow between the sampling valve at the well head and the samplers by tygon-tubing hose connections. Upon removal of all entrained air bubbles from the through-flow, the high-pressure valves were closed in the case of the ${ }^{85} \mathrm{Kr}$ sample, or the copper tubes were pinched closed by a wrench for the noble gas sample, sealing the airless water sample in their respective vessels.

All analyses were completed at the Nuclear Chemistry Division of Lawrence Livermore Lab unless otherwise stated. Standard crrors and detection limits are listed in Table 1. Analyses for field ${ }^{3} \mathrm{H}$ were completed using standard scintillation counting techniques at the NTS.

The Te for ${ }^{\circ} \mathrm{Te}$ determination was separated and concentrated by resins and analyzed hy liquid scintillation counting (Silva et al., 1986). One liter of the sample was 
oxidized with $\mathrm{HCl}$ and $\mathrm{H}_{2} \mathrm{O}_{2}$ and mixed with 0.5 grams of $\mathrm{AG} 1 \times 8$ (100-200 mesh) anion resin. After 4 hours of stirring, the resin was separated and stacked in a column, and then converted from the chloride form to the perchlorate form with $2 \mathrm{cc}$ of $\mathrm{NaClO}_{4}$. The Tc was reduced and eluted from the column with a $1 \mathrm{M} \mathrm{NaClO}_{4}-0.02 \mathrm{M} \mathrm{Na}_{2} \mathrm{SO}_{3}$ solution. Two milliliters of the sample was mixed with $15 \mathrm{cc}$ of scintillation cocktail and counted.

In the $\mathrm{Sr}$ purification for ${ }^{90} \mathrm{Sr}$ analysis, the water sample was mixed with a $2 \mathrm{mg} \mathrm{Sr}$ carrier, evaporated down to a dry residue in a teflon beaker and then redissolved with $2 \mathrm{cc}$ of $6 \mathrm{~N} \mathrm{HNO}_{3}$. The dissolved sample was loaded onto a Sr-Spec resin column and washed 6 times with $6 \mathrm{~N} \mathrm{HNO}_{3}$ (Horwitz et al., 1990). The $\mathrm{Sr}$ was removed from the resin with $0.05 \mathrm{~N} \mathrm{HNO}_{3}$, mixed with a $20 \mathrm{mg}$ yittrium carrier, and equilibrated for 28 days allowing ${ }^{90} \mathrm{Y}$ to grow. The $\mathrm{Y}$ was then separated from the $\mathrm{Sr}$ by the same resin technique as above. A saturated solution of $\left(\mathrm{NH}_{4}\right)_{2} \mathrm{C}_{2} \mathrm{O}_{4}$ was added to the $\mathrm{Y}$ extract. The mixture was then filtered and the residue ashed into a yittrium oxide. The oxide was sandwiched between mylar and beta counted.

The ${ }^{60} \mathrm{Co},{ }^{125} \mathrm{Sb},{ }^{137} \mathrm{Cs}$ activities were counted using a cylindrical Marinelli beaker with a well design for a standard up-looker cryostat (Failor et al., 1988). The cryostat contains a high purity germanium gamma-ray detector. Samples were untreated and counted for approximately 1 week. Raw data was reduced using the GAMANAL program (Gunnink and Niday, 1972).

The ${ }^{36} \mathrm{Cl}$ was extracted by precipitating a quantitative yield of $\mathrm{Cl}$ from the water by adding $\mathrm{AgNO}_{3}$ and precipitating a $\mathrm{AgCl}$ solid (Bentley et al., 1986). The $\mathrm{AgCl}$ was then dissolved in $\mathrm{NH}_{4} \mathrm{OH}$ to precipitate out any sulfates. The aqueous solution was filtered and $\mathrm{AgCl}$ was reprecipitated by acidification. The precipitate was then washed, dried-down, and packed into an aluminum target. The ${ }^{36} \mathrm{Cl}$ was separated from the $\mathrm{AgCl}$ by Cs source ionization and accelerator mass spectrometry (Elmore et al., 1979), and the analysis was reported as a ratio of $36 \mathrm{Cl}$ to total $\mathrm{Cl}$ in the water. 
The inorganic carbon was extracted from the sample by vacuum line acid stripping of the water using $5 \mathrm{ml}$ of $100 \%$ phosphoric acid to acidify the sample to a pH $<1$. Carbon dioxide liberation from the sample was further facilitated by an ultrapure nitrogen carrier gas. The $\mathrm{CO}_{2}$ was cryogenically trapped and separated from the water. The $\mathrm{CO}_{2}$ was split for ${ }^{13} \mathrm{C}$ analysis by stable isotope mass spectrometry, completed at the University of California, Davis Geology Department. The carbon dioxide for ${ }^{14} \mathrm{C}$ was reduced on a separate vacuum line to graphite using a cobalt catalyst and hydrogen gas at a $570^{\circ} \mathrm{C}$ reaction temperature, and ${ }^{14} \mathrm{C}$ concentrations were determined by accelerator mass spectrometry.

For ${ }^{87} \mathrm{Sr} /{ }^{86} \mathrm{Sr}$ ratio determination, the water sample was evaporated down to a dry residue in a teflon beaker and then redissolved with $2 \mathrm{cc}$ of $6 \mathrm{NHNO}_{3}$. The dissolved sample was loaded onto a Sr-Spec resin column and washed 6 times with $6 \mathrm{~N} \mathrm{HNO}_{3}$ (Horwitz et al., 1990). The $\mathrm{Sr}$ was removed from the resin with $0.05 \mathrm{~N} \mathrm{HNO}_{3}$, and the $\mathrm{Sr}$ extract was dried-down. The residue was baked onto a tantalum filament and analyzed for its ${ }^{87} \mathrm{Sr} /{ }^{86} \mathrm{Sr}$ ratio by thermal ionization mass spectrometry.

For ${ }^{234} U / 238 U$ ratio determination, an aliquot of the water sample was added to a $10 \mathrm{mg} / \mathrm{ml} \mathrm{FeCl}_{2}$ solution. The mixture was adjusted to $\mathrm{pH} 8$ with $\mathrm{NH}_{4} \mathrm{OH}$ and the $\mathrm{U}$ was precipitated out with $\mathrm{Fe}(\mathrm{OH})_{3}$ (Goldberg et al., 1963). The precipitate was collected, acidified, and the $U$ was separated with a uranium specific resin. The $U$ extract was dried-down, baked onto a triple Re filament, and its ${ }^{234} \mathrm{U} / 238 \mathrm{U}$ ratio was determined by thermal ionization mass spectrometry.

The $\mathrm{Kr}$ for ${ }^{85} \mathrm{Kr}$ analysis was separated by gas chromatography. Thirty $\mathrm{cm}^{3}$ STP $\mathrm{Kr}$ carrier were added to the sample. The water was frozen to $-77^{\circ} \mathrm{C}$ and the remaining gas was collected onto activated charcoal at $-196^{\circ} \mathrm{C}$. The $\mathrm{O}_{2}, \mathrm{~N}_{2}$, and Ar were separated from the $\mathrm{Kr}$ by a He elution at $-36^{\circ} \mathrm{C}$. The $\mathrm{Kr}$ was transferred at $23^{\circ} \mathrm{C}$ to a $5 \mathrm{~A}$ molecular sieve at $-196^{\circ} \mathrm{C}$. The temperature was raised to $-36^{\circ} \mathrm{C}$ and the $\mathrm{Kr}$ was collected on activated charcoal with yields of about $95 \%$ and purities of about $99 \%$. The $\mathrm{Kr}$ was 
loaded into thin window Beta counting cells and counted for 360 mins with an external detector of $8 \%$ efficiency.

For ${ }^{3} \mathrm{He} /{ }^{4} \mathrm{He}$ determination the sample was attached to the noble gas sample manifold with an all metal helium-tight seal and the section was evacuated. The water sample was released by removing a clamp and re-rounding the pinched copper tube. The water was collected in a $200 \mathrm{~cm}^{3}$ volume. The water was frozen with liquid nitrogen after $10 \mathrm{~min}$, where the majority of the $\mathrm{He}(>99 \%)$ was left in the gas phase. Active gases were removed with a hot Ti-Al alloy $\left(400^{\circ} \mathrm{C}\right)$ getter. Argon, krypton and xenon were collected on activated charcoal at liquid nitrogen temperature. Helium and neon were collected on activated charcoal at $-263^{\circ} \mathrm{C}$. The helium was then released into the mass spectrometer at $-238^{\circ} \mathrm{C}$. The mass spectrometer was operated at a resolving power of about 600 and the HD peak was completely resolved from the ${ }^{3} \mathrm{He}$ peak. The mass 3 detector was a 17 stage dynode electron multiplier. The mass 4 detector was a faraday cup. The relative sensitivity of the two detectors was calibrated by analyzing samples of air helium with ${ }^{3} \mathrm{He} /{ }^{4} \mathrm{He}=1.40 \times 10^{-6}$.

For determination of the $\mathrm{He}, \mathrm{Ne}, \mathrm{Ar}, \mathrm{Kr}$ and $\mathrm{Xe}$ abundances the water sample was released into a $200 \mathrm{~cm}^{3}$ volume as described in step 1 above except that just prior to release, a standard quantity of ${ }^{3} \mathrm{He},{ }^{21} \mathrm{Ne},{ }^{38} \mathrm{Ar},{ }^{80} \mathrm{Kr}$ and ${ }^{124} \mathrm{Xe}$ were added to the volume from a gas aliquotting system (2 liter reservoir volume plus a $0.2 \mathrm{~cm}^{3}$ aliquotting volume). The water sample was frozen with liquid nitrogen and then thawed and warmed to $50 \mathrm{C}$. The sample was then frozen again with dry ice $\left(-78^{\circ} \mathrm{C}\right)$. This process was to mix the sample gases with the spike gases $\left({ }^{3} \mathrm{He},{ }^{21} \mathrm{Ne},{ }^{38} \mathrm{Ar},{ }^{80} \mathrm{Kr}\right.$ and $\left.{ }^{124} \mathrm{Xe}\right)$. A small aliquot of the gas (1\%) was taken for argon analysis. The gas was purified by exposure to hot $\mathrm{Ti}-\mathrm{Al}$ alloy getters and then the gas was admitted to the mass spectrometer for isotopic analysis. The remaining gas was purified by gettering, and then the $\mathrm{Ar}, \mathrm{Kr}$ and Xe were collected on activated charcoal. The He and Ne were split into two samples. First the He was analyzed, then the Ne was analyzed. The charcoal trap containing the $\mathrm{Kr}$ 
and $\mathrm{Xe}$ was warmed slightly to desorb the Ar, and the Ar was pumped away. The Kr and $\mathrm{Xe}$ were then completely released and admitted to the mass spectrometer. The $\mathrm{Kr}$ and $\mathrm{Xe}$ were measured simultaneously. The measurements were calibrated by using samples of water prepared in the laboratory (mostly at $21^{\circ} \mathrm{C}, 6(x)^{\prime}$ elevation). Analytical uncertainty is approximately $2 \%$.

Analytical Uncertainties - Uncertainties in absolute tritium values arose during the field tritium monitoring at the NTS. A variation in the power supply fed to the Betaman Liquid Scintillation Counter (LSC) in the trailer at the drilling site caused the uncertainties. Subsequent installation of an Uninterrupted Power Supply unit to the Betaman LSC eliminated the uncertainty. A routine check of tritium analyses were conducted for duplicate samples on the Packard LSC at the LLNL trailer in Mercury. Detection limit for the Betaman LSC was $2800 \mathrm{pCi} / \mathrm{L}$, and $400 \mathrm{pCi} / \mathrm{L}$ for the Packard LSC. 


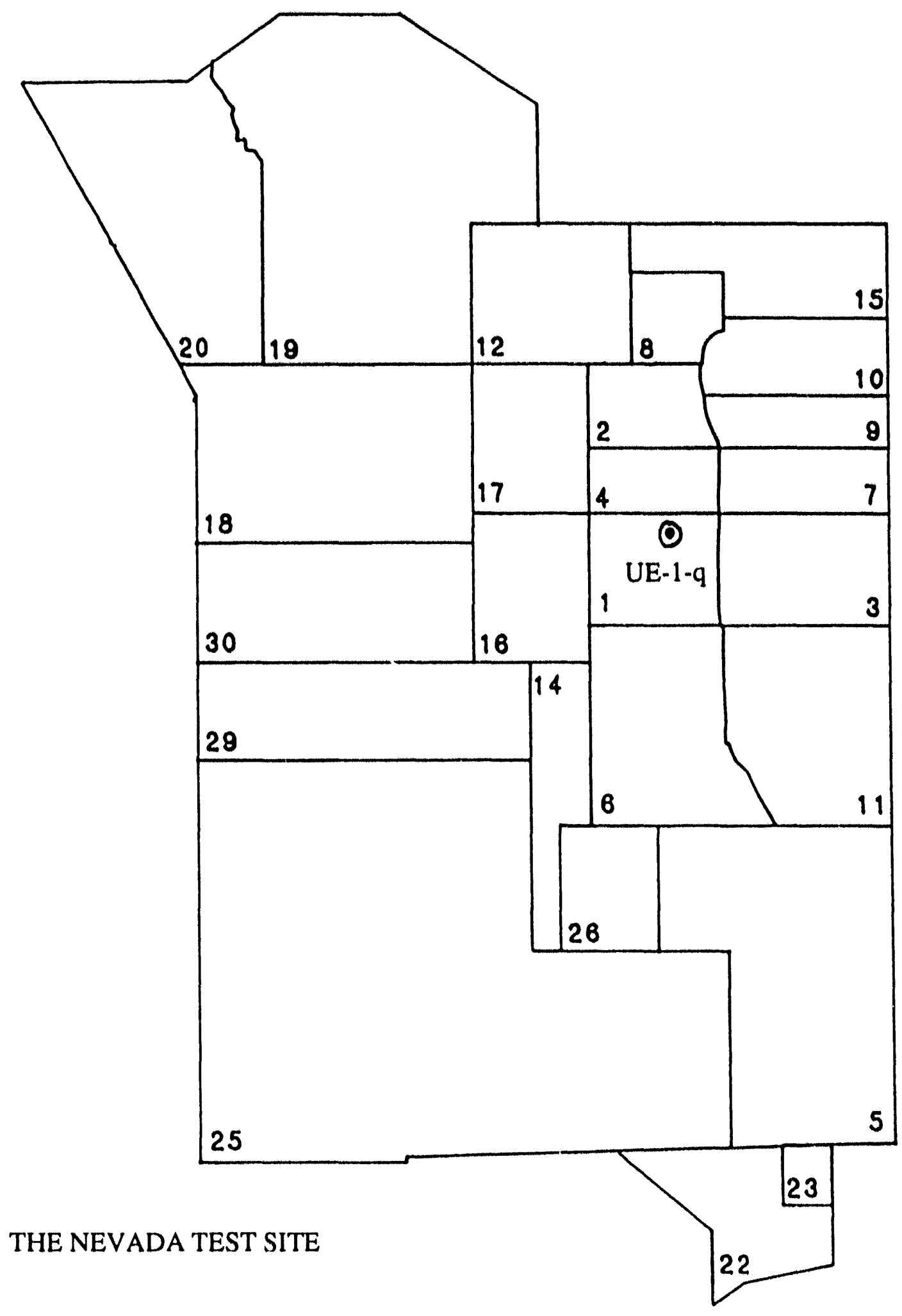

Figure 1 


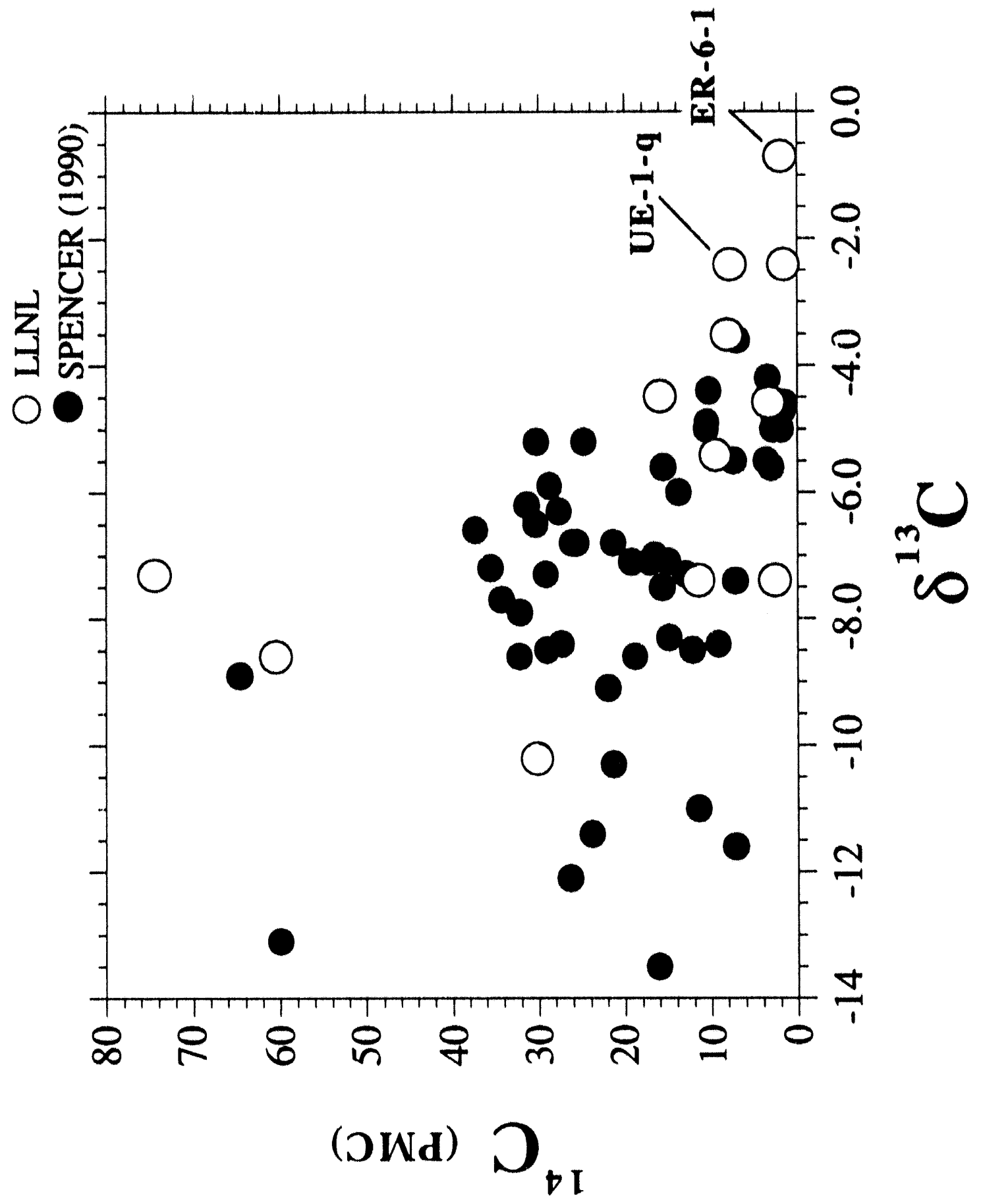




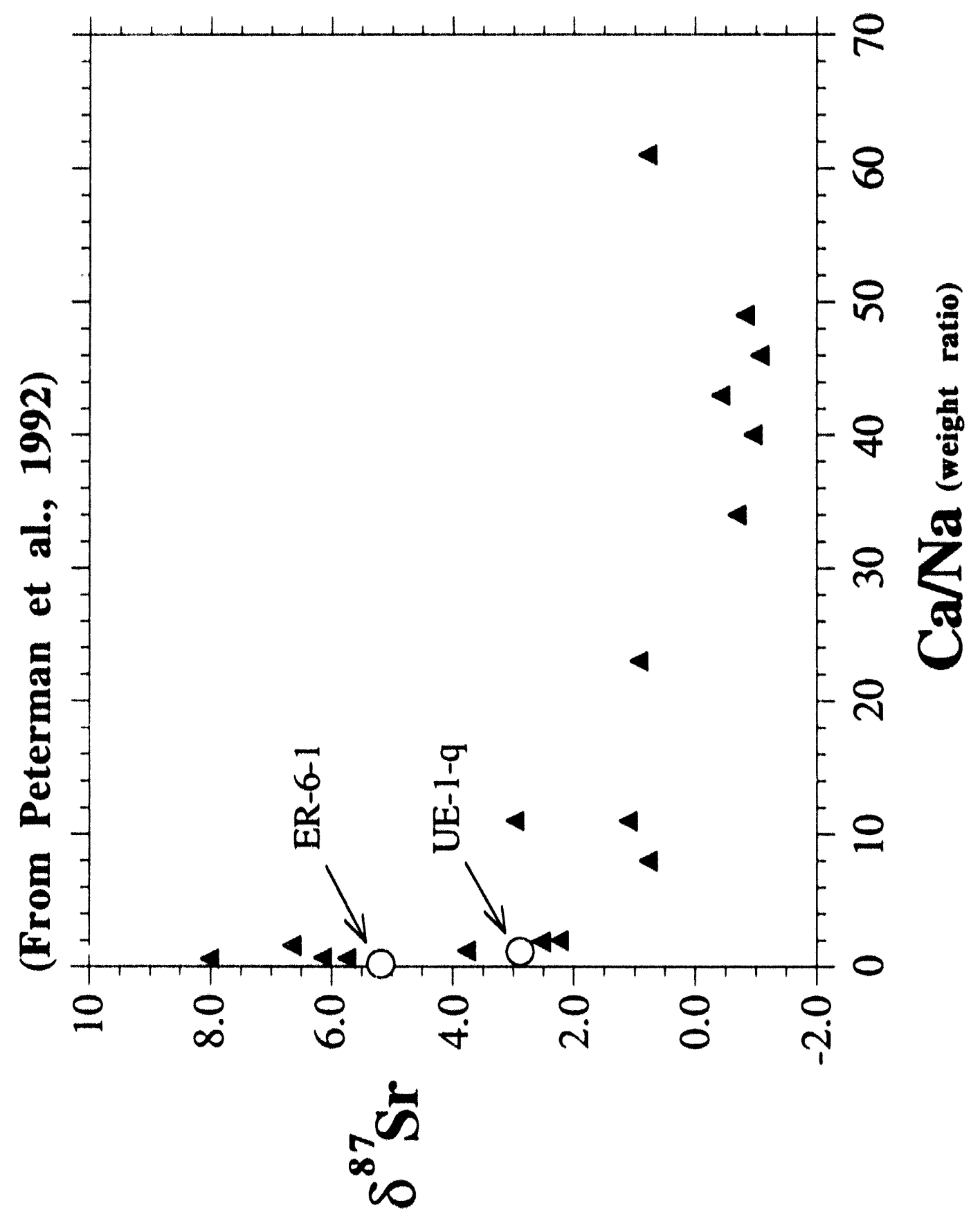




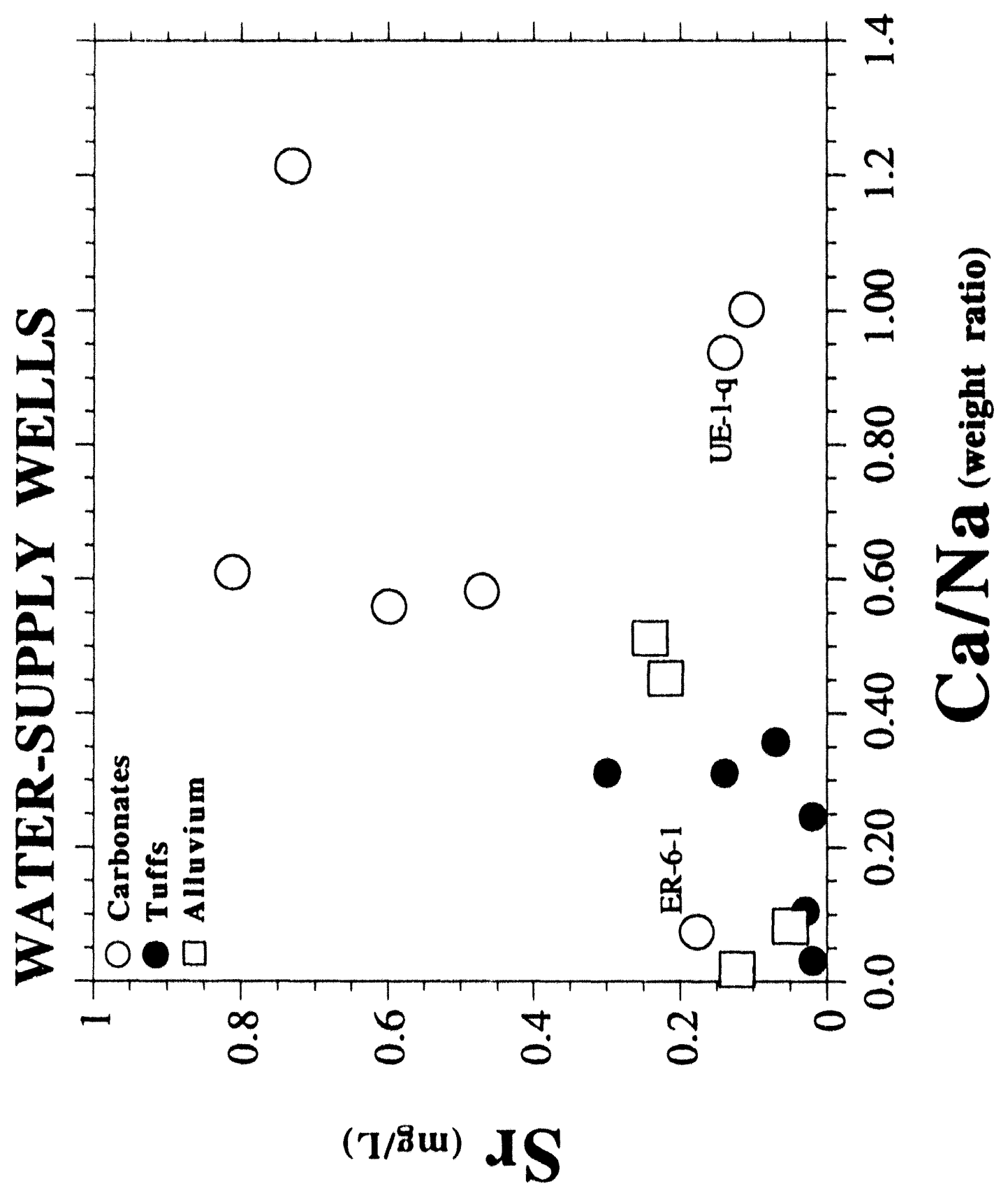




\section{(From Osmond and Cowart, 1982)}

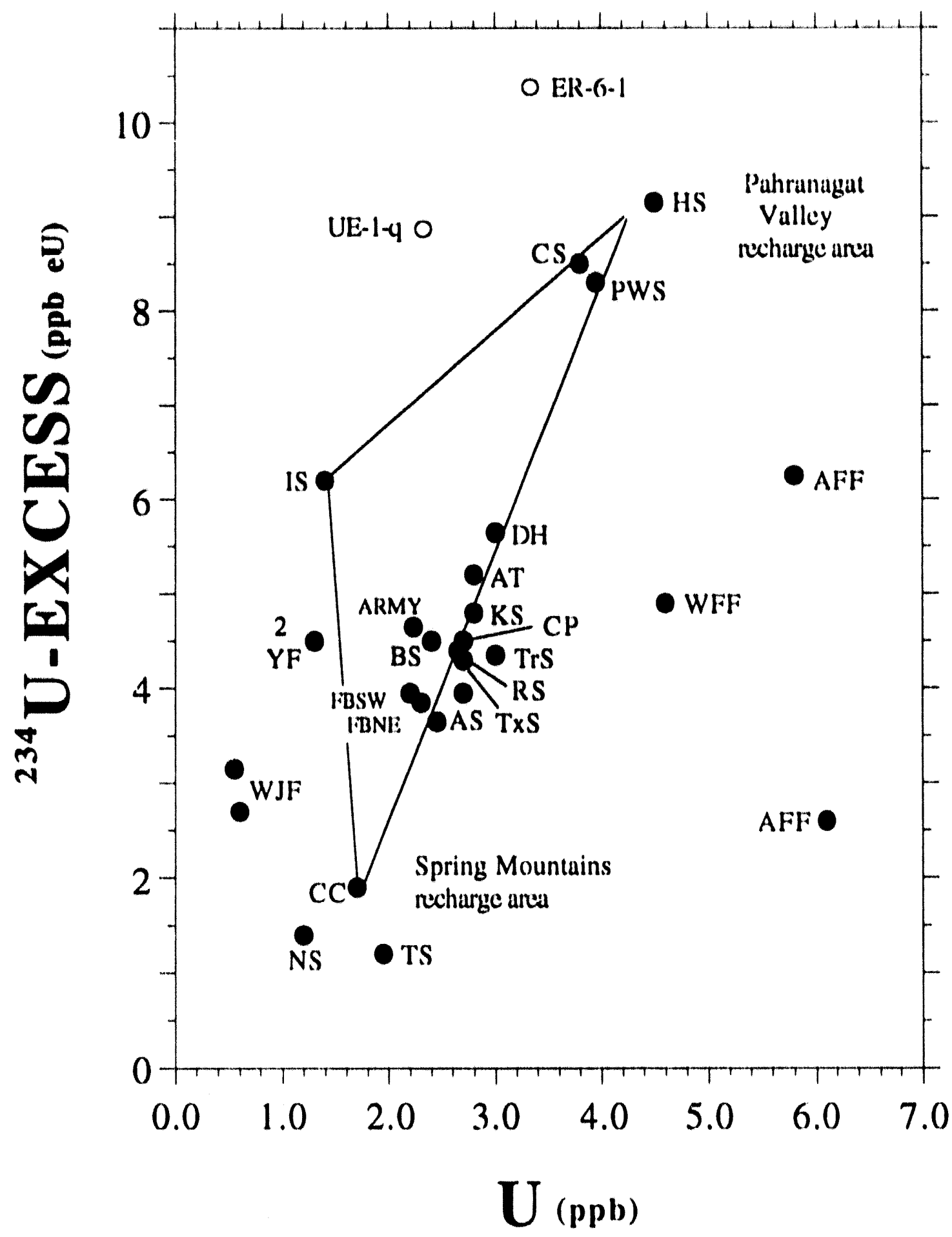

Figure 5 


\section{TABLE D}

WELL I.D.

SAMPLE DATE

SAMPLE QUANTITY
UE-1-4

$7 / 10 / 92$

${ }^{14} \mathrm{C}=1 \mathrm{~L} ;{ }^{3} \mathrm{H} \cdot{ }^{3} \mathrm{He}=1 \mathrm{~L} ;{ }^{36} \mathrm{Cl}=1 \mathrm{~L} ;$

${ }^{60} \mathrm{Co}+{ }^{125} \mathrm{Sb}+{ }^{137} \mathrm{Cs}=1 \mathrm{~L} ;{ }^{90} \mathrm{Sr}=1 \mathrm{~L}$;

${ }^{85} \mathrm{Kr}=1 \mathrm{~L} ;{ }^{90} \mathrm{Tc}=4 \mathrm{~L}$;

${ }^{87} \mathrm{Sr} /{ }^{86} \mathrm{Sr}+234 \mathrm{U} / 238 \mathrm{U}=1 \mathrm{~L}$

\section{Radiochamistry}

3H.3He (pCi/L)

S1.0

${ }^{3} \mathrm{H} \cdot{ }^{3} \mathrm{He}$ upper IImit (pCi/L)

1.0

${ }^{60} \mathrm{Co}(\mathrm{pCi} / \mathrm{L})$

$\leq 0.59$

${ }^{60} \mathrm{Co}$ upper limit (pCi/L)

().59

${ }^{85} \mathrm{Kr}(\mathrm{pC} \mathrm{i} / \mathrm{L})$

$\leq 30$

${ }^{85} \mathrm{Kr}$ upper $1 \mathrm{mmit}(\mathrm{pCi} / \mathrm{L})$

30

90) $\mathbf{S r}(\mathrm{pCi} / \mathrm{L})$

$<0.9$

${ }^{90} \mathrm{Sr}$ upper limit (pCi/L)

$\leq 0.9$

${ }^{99} \mathrm{Tc}(\mathrm{pCi} / \mathrm{L})$

$<4.5$

${ }^{99} \mathrm{Tc}$ upper limit (pCi/L)

4.5

$125 \mathrm{Sb}(\mathrm{pCi} / \mathrm{L})$

$\leq 1.8$

125Sb upper Ilmit (pCi/L.)

1.8

${ }^{137} \mathrm{Cs}(\mathrm{pCi} / \mathrm{L})$

$\leq() .65$

${ }^{137} \mathrm{Cs}$ upper $\mathrm{IImit}(\mathrm{pCi} / \mathrm{L})$

0.65

${ }^{234} \mathrm{U}(\mathrm{pCi} / \mathrm{L})$

4.7

$235 U(p C i / L)$

$(0.012$

238 U (pCi/L)

0.95

${ }^{36} \mathrm{Cl}(\mathrm{pCi} / \mathrm{L}$. 


\section{Eisld Merasumements}

$\mathbf{T}^{\circ} \mathbf{C}$

pH

7.811

$\operatorname{COND}(\mu \mathrm{S})$

D.O. (mg/L)

Alk $\left.(\mathrm{HCO})_{3}\right)$

\section{Environmentuldsolones}

${ }^{14} \mathrm{C}$ (percent modern curbon)

0.0765

${ }^{1.3} \mathrm{C}(\%)$

.2 .4

${ }^{14} \mathrm{C}$ uncorrected age (yrs)

20,650

${ }^{14} \mathrm{C}$ error $(\%)$

$\leq 5$

${ }^{36} \mathrm{Cl} / \mathrm{Cl}$

$7.90 \times 1()^{-13} \pm 1.6 \times 1\left(0^{-14}\right.$

[Cl] $(\mathrm{mg} / \mathrm{h})$

5.27

${ }^{36} \mathrm{Cl}$ atoms/L

$7.10 \times 10^{7}$

${ }^{87} \mathrm{Sr} /{ }^{16} \mathrm{Sr}$

$0.711294 \pm 0 .(0)(1) 314$

$8^{47} \mathrm{Sr}$

2.95

${ }^{234} \mathrm{U} / 238 \mathrm{U}$

$0.0(0) 268 \pm 0 .(0 \times)(1.54$

${ }^{234} U / 235 U$

0.0 .3697

${ }^{234} U / 238 \mathrm{U}$ activity ratio

4.87

${ }^{4} \mathrm{He}$ (atoms/ml)

$1.76 \times 1()^{12}$

20 Ne (atoms/ml)

$4.27 \times 1()^{12}$

36Ar (altoms/ml)

$2.51 \times 101.3$

${ }^{82} \mathbf{K r}$ (atoms/ml)

$1.92 \times 10^{11}$

${ }^{129} \mathrm{Xe}(\mathrm{atoms} / \mathrm{ml})$

$5.81 \times 1010$

${ }^{3} \mathrm{He}$ (atoms/ml)

$1.62 \times 10^{6}$

noble gas uncertainty

$2 \%$ 
TABLE 2

WELL Chlorine-36 uge

UE-1-a

UE-19-c

UE-19-h

UE-1-c 1.350)

UE-1.c 1636

UE-1-b

TW-1

ER-6-1

UE-1-4

UE-18-r

FA-WT

FA-1590)

HTH-IUPPER

HTH.ILOWER

HTH-2
Apparent

Carbon-14 age

$\begin{array}{rr}4,192 & 4,2(19 \\ 1,(172,1(1) & 17,737 \\ 75(1), 330 & 19,546 \\ 758,2(0) & 28,987 \\ 761,180 & 28,987 \\ & 14,996 \\ 869,(150) & 9,925 \\ 770,290 & 31,936 \\ 74(1,650) & 21,195 \\ & 20,281 \\ & 9,843 \\ 276,2(X) & 9,342 \\ 484,180 & 33,683 \\ 1,177,300 & 35,288 \\ 1,(080,4(X) & 2,422\end{array}$




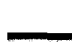

